\title{
POSITRON ANNIHILATION IN INTERNALLY OXIDIZED COPPER
}

\author{
M. Misheva
}

Faculty of Physics, University of Sofia, 5 J. Bourchier blvd., 1126 Sofia, Bulgaria

N. NANCHEVA

Department of Physics, Technical University, Russe 7017, Bulgaria

AND N. Feschiev

Department of Metal Science, Technical University, Russe 7017, Bulgaria

The positron lifetimes in internally oxidized polycrystalline copper, annealed at different temperatures, were measured. It was found that the dispersed alumina particles act as positron traps. Estimation of concentration of defects was made in the frames of the trapping model.

PACS numbers: 78.70.Bj

\section{Introduction}

In many cases there is a necessity of materials which combine high electrical and thermal conductivity with mechanical strength. The latter must retain at comparatively high temperatures.

In general, the strengthening is a result of some obstacles of any kind, present in material, which hinder dislocation motion. Such barriers are, for example, the Guinier-Preston zones, second-phase precipitates etc., which may be formed during quenching or (and) ageing of oversaturated solid solutions.

In internally oxidized alloys, the dislocation motion barriers are highly dispersed oxides of elements less noble than the matrix. In copper such elements are aluminum, magnesium and silicon [1].

It is well established that positrons are effective probe for studying vacancy-type defects (see for example [2]). In some cases the study of precipitation in metals by positron annihilation technique is also possible [3].

The aim of the present study is to elucidate the defect structure of oxide-dispersion-strengthened copper alloy prepared by hard plastic deformation of internally oxidized copper in the Department of Metal Science, Technical University, Russe. 


\section{Material}

The sample material was obtained from $99.9 \%$ copper. After internal oxidation of $\mathrm{Cu}-\mathrm{Al}(0.3 \mathrm{wt} \%)$ alloy for $8 \mathrm{~h}$ at $950^{\circ} \mathrm{C}$, the samples were plastically deformed by pressure to reduce the thickness by $\varepsilon=75 \%$. The volume fraction of alumina is $\approx 1.4 \%$. The size of the alumina particles is $\approx 0.1 \mu \mathrm{m}$.

Some characteristics of the material are shown in Table $I\left(H_{V}\right.$ is the Vickers

\section{TABLE I}

\begin{tabular}{c|c|c|c|c}
\hline \hline$H_{\mathrm{V}}$ & HMV & $D[\AA]$ & $\Delta \alpha / \alpha$ & $\rho\left[\mathrm{cm}^{-2}\right]$ \\
\hline $113-115$ & $\approx 150$ & 636 & 0.0012 & $1.86 \times 10^{11}$
\end{tabular}

hardness (load $P=5 \mathrm{kgf}$ ), HMV - microhardness ( $P=50 \mathrm{gf}$ ), $\rho-$ dislocation density). The effective diameter $D$ of particles and microstrain $\Delta \alpha / \alpha$ were determined by X-ray diffraction.

\section{Experimental details}

Two identical samples with dimensions $10 \times 10 \times 1 \mathrm{~mm}$ were used in this study. A ${ }^{22} \mathrm{Na}$ radioactive source, sealed between two thin $\left(0.723 \mathrm{mg} / \mathrm{cm}^{2}\right)$ kapton foils, was sandwiched by the samples.

The positron lifetime spectrometer used is based on a fast-slow type coincidence circuit and provides about $240 \mathrm{ps}$ time resolution (FWHM).

Analysis of lifetime spectra was performed by the program POSITRONFIT-EXTENDED [4]. About $1.2 \times 10^{6}$ counts were accumulated for each spectrum. The samples were measured 4 to 8 times. Corrections for source lifetime components were made.

The measurements were carried out at room temperature in as-received samples and after 1 hour annealing of the samples successively at 100,240,300 and $430^{\circ} \mathrm{C}$ in air.

The $3 \gamma$ probability was measured in as-received samples with a HPGe spectrometer (energy resolution at the $514 \mathrm{keV}$ gamma line of ${ }^{85} \mathrm{Sr}-1.2 \mathrm{keV}$ ) by the so-called "peak-peak" method [5].

Before each measurement the samples were cleaned by picking in nitric acid.

\section{Results and discussion}

The parameters (lifetimes and intensities) obtained by three-component fit of lifetime spectra are considerably dispersed. The longest lifetimes $\tau_{3}$, however, remain constant in the error limits. Because of this, we tried a three-component analysis with the fixed value of $\tau_{3}$, obtained in as-received samples. The results are shown in Table II. 
TABLE II Lifetimes, intensities and mean lifetime yielded from three-exponential fit of lifetime spectra; $\tau_{3}=2240 \mathrm{ps}-$ fixed.

\begin{tabular}{c|l|l|l|r|l|l|l}
\hline \hline $\begin{array}{c}\text { Treat- } \\
\text { ment }\end{array}$ & $\tau_{1}[\mathrm{ps}]$ & $I_{1}[\%]$ & $\tau_{2}[\mathrm{ps}]$ & $I_{2}[\%]$ & $\tau_{3}[\mathrm{ps}]$ & $I_{3}[\%]$ & $\bar{\tau}[\mathrm{ps}]$ \\
\hline 1 & $184(1)$ & $87.2(6)$ & $437(8)$ & $9.6(5)$ & $2241(18)$ & $3.2(1)$ & $274(3)$ \\
2 & $184(1)$ & $97.4(4)$ & $412(33)$ & $2.1(3)$ & 2240 & $0.39(9)$ & $197(2)$ \\
3 & $129(1)$ & $85.4(6)$ & $277(5)$ & $12.7(9)$ & 2240 & $0.37(6)$ & $156(2)$ \\
4 & $118.3(8)$ & $89.5(5)$ & $276(4)$ & $10.2(5)$ & 2240 & $0.22(2)$ & $139(1)$ \\
5 & $119.7(9)$ & $87.9(6)$ & $285(1)$ & $11.8(5)$ & 2240 & $0.28(5)$ & $145(2)$ \\
\hline
\end{tabular}

1 - as-received samples, 2 - one-hour annealing at $100^{\circ} \mathrm{C}, 3$ - one-hour annealing at $240^{\circ} \mathrm{C}, 4-$ one-hour annealing at $300^{\circ} \mathrm{C}, 5$ - one-hour annealing at $430^{\circ} \mathrm{C}$.

It is evident from the experimental results and their comparison with the theoretical ones [6] that the defect concentration in the as-received and annealed at $100^{\circ} \mathrm{C}$ samples is such that all the positrons annihilate in trapped statcs.

These states and the corresponding lifetimes, in our opinion, are as follows:

(i) Alumina particles $-\tau_{3}$.

As Hirsch et al. [7] have shown, the internal oxidation of dilute $\mathrm{Cu}-\mathrm{Al}$ alloys produces a fine dispersion of alumina particles in the matrix. On the other hand, the value of $\tau_{3}$ is of the order of $2 \mathrm{~ns}$ and it is characteristic of pick-off annihilation of $o$-Ps. While in metals positrons annihilate without formation a bound $\mathrm{e}^{+-\mathrm{e}^{-}}$ state, such state in $\mathrm{Al}_{2} \mathrm{O}_{3}$ is well established [8]. Therefore, this component can be attributed to positron annihilation in alumina precipitates. Moreover, as the probability of $3 \gamma$ annihilation is equal to zero in $3 \sigma$-error limits in as-received samples, one could state that, namely, ortho-positronium is formed in alumina particles and pick-off annihilation takes place.

The conclusion that alumina particles act as positron traps is consistent with the observation of Alam et al. [9] that the heat treatment of dilute $\mathrm{Al}-\mathrm{Mg}$ alloy in the presence of any amount of oxygen in the annealing atmosphere causes great changes in the parameters of positron annihilation.

It is well established [1] that with the increase in annealing temperature, two processes, namely recrystallization of the matrix and coagulation of alumina particles take place. This leads to the increase in interparticle distance. If the distance between alumina particles becomes greater than the diffusion path of positrons in copper, the probability of the positron trapping at the precipitates will decrease. This is consistent with $I_{3}$ changes after annealing of the samples.

(ii) Vacancies connected with dislocations, dislocation loops and border regions between alumina particles and matrix $-\tau_{1}$.

We suppose that $r_{1}$ can be considered as apparent. lifetime of a mixture of three unresolved components due to positron annihilation in three different types 
of traps, created during the internal oxidation and subsequent deformation of the samples.

1. During the oxidation all $\mathrm{Al}$ is removed from the solid solution and, therefore, some purification of the matrix takes place [1]. On the other hand, however, there remain vacancies on the previous $\mathrm{Al}$ sites. At room and higher temperatures, these vacancies are mobile and become trapped at dislocations. Annealing of the samples at $240^{\circ} \mathrm{C}$ removes these traps.

2. The dislocation structure generated by plastic deformation and associated with alumina particles consists predominately of prismatic loops. The number of these loops decreases rapidly with the temperature in the range of $30-230^{\circ} \mathrm{C}$ [7] which can be connected with fast decrease in $\tau_{1}$ after annealing of the samples at $240^{\circ} \mathrm{C}$.

3. Due to the considerable size of the alumina particles $\approx 0.1 \mu \mathrm{m}$, they have lost coherency, presumably by generation of interface dislocations at the temperature of precipitates formation. During the cooling, the difference between thermal contraction coefficients of the particles and of the matrix causes further misfit strains. The effect of particles coagulation during annealing of the samples is the same.

Due to the above mentioned behavior of these three types of traps during annealing of the samples, the shortest lifetime component $\tau_{1}$ in the cases 3,4 and 5 can be interpreted as apparent lifetime of a mixture of two unresolved components due to positron annihilation in the bulk of the matrix and in the border regions between alumina particles and matrix.

(iii) Vacancy clusters $-\tau_{2}$.

The values of the second component $\tau_{2}$ presume the presence of vacancy clusters in the samples. The sizes of these clusters decrease as the annealing temperature increases. Annealing at $100^{\circ} \mathrm{C}$ leads to considerable decrease in concentration of voids without changing their sizes. Annealing at $240^{\circ} \mathrm{C}$ leads to the dissociation of some of them. Subsequent annealing keeps practically unchanged sizes and concentration of clusters.

In the frame of the trapping model [10] for the cases of two and three different types of defects the following estimations were made.

(i) After $430^{\circ} \mathrm{C}$ annealing of the samples.

$$
\tau_{\mathrm{b}}=126 \mathrm{ps}, \quad k_{\mathrm{cl}}=1.8 \times 10^{7} \mathrm{~s}^{-1}, \quad k_{\mathrm{AP}}=0.5 \times 10^{9} \mathrm{~s}^{-1},
$$

where $\tau_{\mathrm{b}}$ is the bulk lifetime, $k_{\mathrm{cl}}$ and $k_{\mathrm{AP}}$ are the positron trapping rates for vacancy clusters and alumina particles respectively. The specific trapping rate in the clusters is $\mu_{\mathrm{cl}}=N \mu_{\mathrm{v}}$, where $N=4$ is the number of vacancies in this case, $\mu_{\mathrm{v}}=4.93 \times 10^{-9} \mathrm{~cm}^{-3} \mathrm{~s}^{-1}[11]$ is the specific trapping rate for a vacancy in copper. Using the upper value for $k_{\mathrm{cl}}$, the cluster concentration was estimated to be $C_{\mathrm{cl}}=2.5 \times 10^{16} \mathrm{~cm}^{-3}$.

(ii) As-received samples.

$$
\begin{aligned}
& k_{\mathrm{d}}=2.83 \times 10^{11} \mathrm{~s}^{-1}, \quad k_{\mathrm{cl}}=31.4 \times 10^{9} \mathrm{~s}^{-1}(N=20), \\
& C_{\mathrm{cl}}=3.2 \times 10^{17} \mathrm{~cm}^{-3}, \quad k_{\mathrm{AP}}=10.6 \times 10^{9} \mathrm{~s}^{-1} .
\end{aligned}
$$

$k_{\mathrm{d}}=\mu_{\mathrm{d}} \rho$ is the positron trapping rate for dislocations $\left(\mu_{\mathrm{d}}=1.51 \mathrm{~cm}^{2} \mathrm{~s}^{-1}[11]\right)$. 
This work was partially supported by the Bulgarian National Science Foundation under contract No. PH56.

\section{References}

[1] E.P. Danelia, W.M. Rozenberg, Internally Oxidized Alloys, Metallurgiya, Moskva 1978 (in Russian).

[2] A. Seeger, F. Banhart, Helv. Phys. Acta 63, 403 (1990).

[3] G. Dlubek, O. Brümmer, J. Yli-Kauppila, P. Hautojärvi, J. Phys. F, Met. Phys. 11, 2525 (1981).

[4] P. Kirkegaard, M. Eldrup, Comput. Phys. Commun. 7, 401 (1974).

[5] P.U. Arifov, in: Methods of Positron Diagnostics and Interpretation of the Positron Annihilation Spectra, Ed. P.K. Habibulaev, FAN, Tashkent 1985; p. 33 (in Russian).

[6] H. Hakkinen, S. Makinen, M. Manninen, Department of Physics, University of Jyvaskyla, Finland, Preprint No 22/1989.

[7] P. Hirsch, F. Humphreys, Proc. R. Soc. Lond. A 318, 45 (1970).

[8] G.M. Bartenev, A.D. Tsỹganov, E.P. Prokop'ev, A.Z. Varisov, Usp. Fiz. Nauk 103, 339 (1971) (in Russian).

[9] A. Alam, H.P. Leighli, R.V. West, J. Phys. F, Met. Phys. 12, 399 (1989).

[10] A. Vehanen, P. Hautojärvi, J. Johansson, J. Yli-Kauppila, P. Moser, Phys. Rev. B 25, 762 (1982).

[11] L. Lepisto, J. Yli-Kauppila, P. Kettunen, P. Hautojärvi, Phys. Status Solidi A 67, K93 (1981). 